are thought to be largely unaffected by the environment, with the result that similarity of DNA sequence more accurately reflects relationships. The reality of sequence evolution is more complex than this statement suggests, making difficult the retrieval of phylogenetic signals from such ancient divergences. Friedrich and Taut ${ }^{2}$ have analysed the largest arthropod DNA sequence data set so far from the small and large subunit ribosomal RNA genes of a carefully selected range of taxa. Importantly, they have also taken pains to test for and control several factors known to bias the recovery of the correct phylogeny.

Boore et al. ${ }^{1}$ use molecular data in a manner more familiar to traditional systematists. They have looked for gene rearrangements within the small mitochondrial genomes of animals ( 37 genes, usually) and used gene boundaries as characters to produce a phylogenetic tree. These rearrangements occur only rarely and are considered to be immune to selective pressures. The vast number of potential rearrangements makes identical novel arrangements in unrelated taxa extremely unlikely. Events such as these provide ideal characters for phylogenetic analysis. Both studies provide further strong support for a monophyletic Arthropoda, a concept particularly strengthened by the novelty of the data of Boore et al., who also tentatively include the lobopods in this assemblage.

The one grouping common to virtually all previous schemes relating the arthropods is the close relationship of the myriapods and insects; a group united by the common possession of several adult characteristics and often referred to as the atelocerates. The existence of the Atelocerata is disputed by the study by Friedrich and Tautz, who suggest that it is the crustaceans and not the myriapods that are the sister group of the insects (incidentally placing the origin of the myriapods earlier than their fossil record suggests) ( $b$ in the figure). Boore et al. also present data that support this conclusion. Their interpretation of their data is cautious, however, and they do not separate the traditional atelocerate clades on their summary diagram. The closeness of the insects and crustaceans had been supported by some, but not all, previous molecular analyses ${ }^{7-9}$

If the close relationship of the crustaceans and insects is accepted, features shared by myriapods and insects, but not the crustaceans, must be shown either to be shared as a result of convergence, most likely because both are terrestrial groups, or to be primitive characteristics secondarily lost in the Crustacea.

The following characters have traditionally been used to unite the myriapods and insects: unbranched legs, a tracheal system, malphigian tubules, absence of appendages corresponding to the second antennae of crustaceans, and a mandible composed of a whole limb (crustacean mandibles are formed from a limb base). Friedrich and Tautz argue that the first four of these characters are shared through convergence due to both groups being terrestrial; structures similar to the first three are even found in some terrestrial arachnids. Finally, recent gene expression data argues against a whole limb mandible in the insects. The gene Distalless, generally expressed in the tip of insect appendages, is not expressed in the insect mandible ${ }^{10}$. This suggests that the appendage tip is missing and that the insect mandible is, in fact, similar to that of the crustaceans. Indeed, KukalováPeck ${ }^{6}$ claims that a limb-base mandible is present in all arthropods.

Other lines of evidence support a sister group relationship between insects and crustaceans $^{11}$. Nervous system development in the two groups is strikingly similar ${ }^{12}$, with no equivalent similarity yet seen in myriapods or chelicerates and, again on a cellular level, crustacean and insect eyes are more similar to each other than either are to those of myriapods or chelicerates $^{13}$.

Despite their convincing congruence, these results are unlikely to be immediately generally accepted and many questions remain. More needs to be done to pin down the position of the lobopods, as well as the positions of other less well known groups such as the tardigrades and pycnogonids (sea spiders). The monophyly or otherwise of both the myriapods and the crustaceans also remains uncertain. The position of the chelicerates is still not clear and will determine whether a revised concept of the Mandibulata survives. It seems unlikely that we will have to wait another 150 years for answers to these questions and with them will come a much improved understanding of the evolution of arthropod body form.

Maximilian J. Telford and Richard $\mathrm{H}$. Thomas are in the Department of Zoology, The Natural History Museum, Cromwell Road, London SW7 5BD. UK.

\footnotetext{
1. Boore, J. L., Collins, T. M., Stanton, D., Daehler, L. L. \& Brown, W. M. Nature 376, 163-165 (1995)

2. Friedrich. M. \& Tautz, D. Nature 376, 165-167 (1995)

3. Manton, S. M. The Arthropoda: Habits, Functional Morphology and Evolution (Clarendon, Oxford, 1977) . Cisne, J. L. Science 186, 13-18 (1974)

5. Wills, M. A. . Briggs, D. E. G., Fortey, R. A. \& Wilkinson, M Verh. dt. zool. Ges. (in the press).

6. Kukalová-Peck, J. Can. J. Zool 70, 236-255 (1992).

7. Turbeville, J. M. Pfeifer, D. M., Field, K. G. \& Raff, R. A. Molec. Biol. Evol. 8, 669-686 (1991)

8. Ballard, J. W. O. et al. Science 258, 1345-1348 (1992)

9. Wheeler, W. C. Cartwright, P. \& Hayashi, C. Y. Cladistics 9. 1-39 (1993).

10. Panganiban, G., Nagy, L. \& Carroll, S. B. Curr. Biol. 4, 671-675 (1994)

11. Averof. M. \&Akam, M. Phil. Trans. R. Soc. Lond. B347. 293-303 (1995).

12. Whitington P. M Leach, D. \& Sandeman, R. Development 118, 449-461 (1993)

13. Paulus, H. F. in Arthropod Phylogeny (ed. Gupta, A. P.) 299-383 (Van Nostrand Reinhold, New York, 1979)
}

\section{The sap also rises}

ALL plants are pumps. They take in water through their roots and transpire it as vapour from their leaves. How do they lift the water? Capillary rise is limited to a metre or so, and an atmospheric suction pump cannot lift water above 10 metres; yet trees can grow 100 metres high. Furthermore, aquatic plants cannot use either mechanism, but still thrive; and even land plants survive flooding.

Daedalus reckons that plants move their internal fluids just as we do: by mechanical pumping. Their internal channels form a distributed peristaltic pump, driven by the ceaseless shaking of the wind. On this view, the gallant waving of a wind-blown field of corn, the ceaseless rustling of forest leaves, even Wordsworth's daffodils "tossing their heads in sprightly dance" have stern biological purpose in their movements.

This theory is supported by a recent finding that many commercial plants, such as tomatoes, aubergines and cucumbers, benefit from the repeated bending of their stems by stroking. They develop a darker green, and grow more compactly, as if the added massage saved them from having to grow extended fronds to catch the wind. DREADCO gardeners are now testing this notion. They are shaking selected plants in a range of frequencies and vibrational modes to discover the most effective pumping regimes. Control plants are being clamped rigidly immobile to see if their growth is stunted. Once the technique has been optimized, vibrohorticulture should speed the sap through crops of all kinds, boosting their metabolism and growth.

For the smaller plants, a standard laboratory shaker should be ideal. Trays of seedlings could easily be vibrated at whatever frequency and amplitude optimized their growth. Very large single plants, such as trees, might also be driven mechanically by ropes or hydraulic rams under programmed control. But for crops such as corn, maize and oats, wind seems the best shaker. $A$ field could be set with big baffles to funnel and direct it, spring-loaded vanes to release a stream of vortices downwind, or huge tuned pipes to resonate at the best frequencies. As the crop matured, these could be adjusted to maintain the optimum pattern of vibration.

Aquatic plants would be easier to vibrate. Daedalus is designing special stirrers for watercress beds, and a central wave machine to spread waves out into a rice paddy-field. He also advocates the planting of seaweed on breakwaters and sea defences. The rougher the waves, the more the weed would grow to damp them. David Jones 